\title{
Ultrasound Echogenicity of Papillary Thyroid Cancer Is Affected by Tumor Growth Patterns and Tumor Fibrosis
}

\author{
YUN-SUNG LIM ${ }^{1}$, YOON SE LEE ${ }^{2}$, JIN-CHOON LEE ${ }^{3}$, SEOK-MAN SON ${ }^{4}$, \\ DONG-HOON SHIN ${ }^{5}$, SANG SOO KIM ${ }^{6}$, IN-JU KIM ${ }^{6}$ and BYUNG-JOO LEE ${ }^{7}$ \\ ${ }^{1}$ Department of Otorhinolaryngology-Head and Neck Surgery, Ilsan Hospital, \\ Dongguk University, Goyang, Republic of Korea; \\ ${ }^{2}$ Department of Otorhinolaryngology-Head and Neck Surgery, \\ Asan Medical Center, University of Ulsan College of Medicine, Seoul, Republic of Korea; \\ ${ }^{3}$ Department of Otorhinolaryngology-Head and Neck Surgery, Pusan National University \\ School of Medicine and Biomedical Research Institute, Yangsan, Republic of Korea; \\ ${ }^{4}$ Internal Medicine, Pusan National University School of Medicine \\ and Biomedical Research Institute, Yangsan, Republic of Korea; \\ ${ }^{5}$ Pathology, Pusan National University School of Medicine and \\ Biomedical Research Institute, Yangsan, Republic of Korea; \\ ${ }^{6}$ Department of Internal Medicine, Pusan National University \\ School of Medicine and Biomedical Research Institute, Busan, Republic of Korea; \\ ${ }^{7}$ Otorhinolaryngology-Head and Neck Surgery, Pusan National University \\ School of Medicine and Biomedical Research Institute, Busan, Republic of Korea
}

\begin{abstract}
Background/Aim: The association between preoperative ultrasound (US) echogenicity and histopathological characteristics of papillary thyroid cancer (PTC) has been rarely investigated is not well characterized. This study evaluated a relationship between the clinical characteristics of PTC, histopathological phenomena including tumor growth patterns (TGPs) and tumor fibrosis (TF), and US echogenicity. Patients and Methods: In total, 170 patients with PTC $(<2 \mathrm{~cm})$ underwent total thyroidectomy with central neck dissection. Demographics, US echogenicity, tumor size, extra-thyroidal extension (ETE), lymph node metastasis (LNM) within the central and lateral neck, TGPs, and TF percentage were
\end{abstract}

This article is freely accessible online.

Correspondence to: Byung-Joo Lee, Department of Otorhinolaryngology-Head and Neck Surgery, Pusan National University School of Medicine and Biomedical Research Institute, $1-$ 10 Ami-Dong, Seo-Gu, Busan 49241, Republic of Korea. Tel: +82 512407335/7336, Fax: +82 512468668, e-mail: voiceleebj@gmail.com and Dong-Hoon Shin, Department of Pathology, Pusan National University School of Medicine and Biomedical Research Institute, Yangsan, Kyeongnam 50612, Republic of Korea. Tel: +82553601860 , Fax: +82 553601865, e-mail: donghshin@chol.com

Key Words: Papillary thyroid cancer, ultrasonography, tumor growth pattern, tumor fibrosis, metastasis. reviewed. Results: Patients with TGP II (encapsulated growth with partial pericapsular extension) and III (infiltrative growth) were more frequently burdened by ETE and lateral neck LNM compared to patients with TGP I (encapsulated growth with a well-defined cystic or solid characteristic). Older age was significantly deterministic of TGP III, and male gender and higher TF percentage were independent risk factors for lateral neck LNM. TGP III and TF were independent determining factors for marked hypoechogenicity on US. Conclusion: PTC with TGP II and III and higher tumor fibrosis exhibited more aggressive clinicopathologic behaviors. TGP III and TF were determinants for marked hypoechogenicity.

Metastasis of papillary thyroid cancer (PTC) to the cervical nodes is considered quite common; indeed, occult metastasis has been found to occur in $50-60 \%$ of cases $(1,2)$. Although the clinical significance of nodal metastasis and the efficacy of elective neck dissection are uncertain, lymph node (LNM) metastasis to the neck is associated with an increased risk of regional recurrence (3-5) and a higher rate of distant metastasis (6). Ultrasound (US) is the most commonly used diagnostic tool for preoperative staging of PTC. Preoperative tumor characteristics on US, such as tumor size, echogenicity, and tumor contact with capsule, are of considerable prognostic value (7). Notably, marked hypoechogenicity is reported to be predictive of LNM within the central compartment, especially in papillary thyroid microcarcinoma (8). 

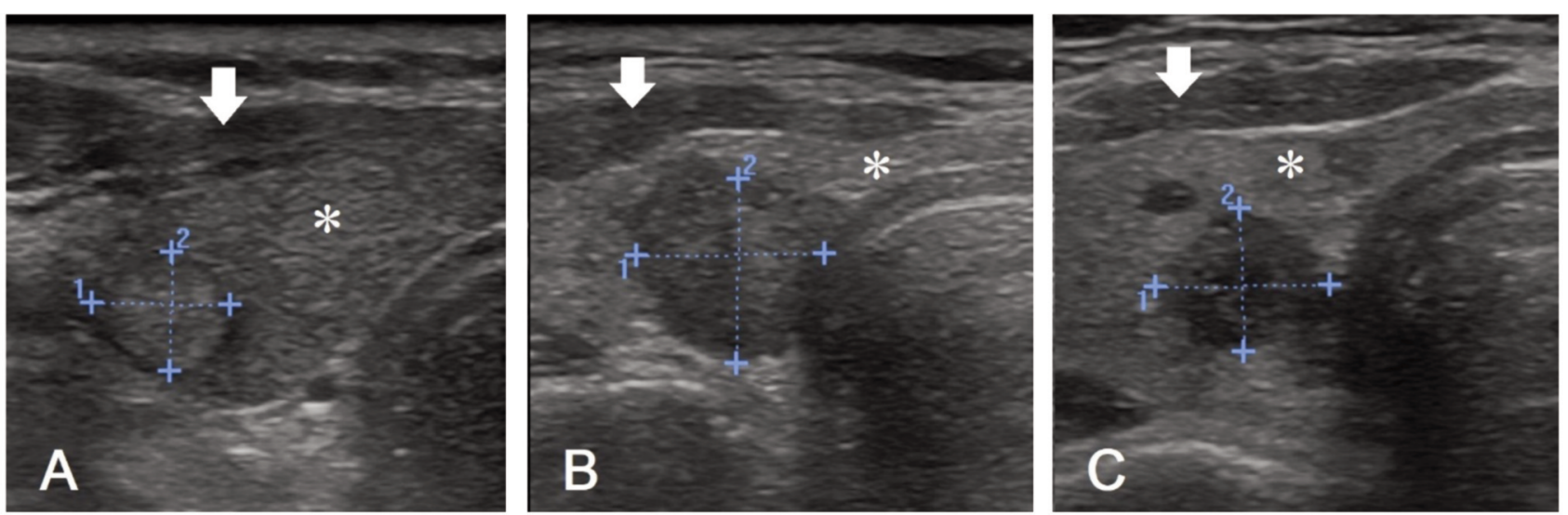

Figure 1. Three kinds of echogenicity demonstrated by ultrasound imaging. (A and B) The thyroid nodules (area defined by blue crosses) demonstrate the same echogenicity as the normal thyroid tissue (asterisks) (A) and the strap muscle (arrows) (B), which were recorded as isoechoic and hypoechoic. (C) The thyroid nodule with a well-defined spiculated margin in the right thyroid gland shows decreased echogenicity compared to the surrounding strap muscle (arrow), and it was recorded as marked hypoechoic.

Diligent efforts have been made to ascertain predictive factors for LNM and recurrence based on histopathological characteristics of the tumor. Factors predictive of an aggressive tumor behavior include: i) loss of cellular polarity and cohesiveness, ii) hobnail feature, iii) invasive tumor growth, and iv) lateral tubular growth (9-14). Invasive tumor growth patterns (TGPs) with an infiltrative tumor border are regarded to be predictive of LNM in PTC (13). Tumor fibrosis (TF), superficial tumor location, and intraglandular tumor spread/multifocality combined with the $B R A F$ mutation can be used in a molecular-pathologic risk stratification model for a better prediction of aggressive tumors (15).

Although several investigations have been conducted regarding US characteristics as well as tumor histopathology as predictive indicators of aggressive tumor behavior, such as in LNM, there are only a few reports associating the preoperative US echogenicity and histopathological characteristics of the tumor. In this study, we aimed to evaluate the effect of TGPs and TF on the clinical behavior of PTC and analyze the relationship between these two histopathological characteristics and US echogenicity for a better preoperative understanding of the tumor's behavior and management.

\section{Patients and Methods}

Study population. Between March 2007 and April 2009, 537 patients diagnosed with PTC underwent surgery at our institution. We collected information of 170 patients with a primary tumor size of less than $2 \mathrm{~cm}$. Revisional cases, tumor size over $2 \mathrm{~cm}$, and histologic variants other than conventional PTC were excluded. All patients underwent near-total or total thyroidectomy with routine central-compartment neck dissection based on the 2006 guidelines of the American Thyroid Association (16). If multiple thyroid tumors were observed on the preoperative US, paratracheal lymph node dissection was performed on the side where the largest tumor was located. Preoperative assessment for cervical LNM included a high-resolution US scan, fine needle aspiration cytology, and a computerized tomography (CT) scan. If there was preoperative evidence of LNM in the lateral neck by preoperative US-guided fine-needle aspiration, lateral compartment dissection was performed. This study was approved by the Pusan National University Hospital Research Ethics Review Board, who granted a waiver of consent for access to clinicopathological records from each participant (H-2003-016-089). All study methodologies were carried out under the guidelines and regulations of the Pusan National University Hospital Research Ethics Review Board.

Ultrasound assessment. The examination was performed by an experienced endocrinologist (SSK) using a US scanner (Vivid i; GE Healthcare, Milwaukee, WI, USA) equipped with a $10-$ to $13-\mathrm{MHz}$ linear probe. Echogenicity of the tumor was evaluated and categorized as i) isoechogenicity, ii) hypoechogenicity, and iii) marked hypoechogenicity. We defined marked hypoechogenicity as decreased echogenicity compared to that in the surrounding strap muscle. The thyroid nodules demonstrating the same echogenicity as that of the strap muscle and the normal thyroid tissue were recorded as hypoechoic and isoechoic (Figure 1) (17).

Histopathological evaluation including TGPS/TF. Pathologic data of tumor size, extrathyroidal extension (ETE), and LNM in the central and lateral neck were reviewed. TGPs and TFs were retrospectively measured by an experienced head and neck pathologist (DHS). Three kinds of TGPs were defined: i) a welldefined encapsulated growth with a cystic or solid characteristic, ii) an encapsulated growth with partially pericapsular tumor extension, iii) an infiltrative tumor growth (stellate and spiculated margin) (Figure 2). TF was estimated by the percentage of a fibrotic area within the tumor (Figure 3 ).

Statistical analysis. The $\chi^{2}$ test or Fisher exact test was used to rule out the role of chance in any associations between pathologic parameters and LNM. Factors related to US echogenicity were 

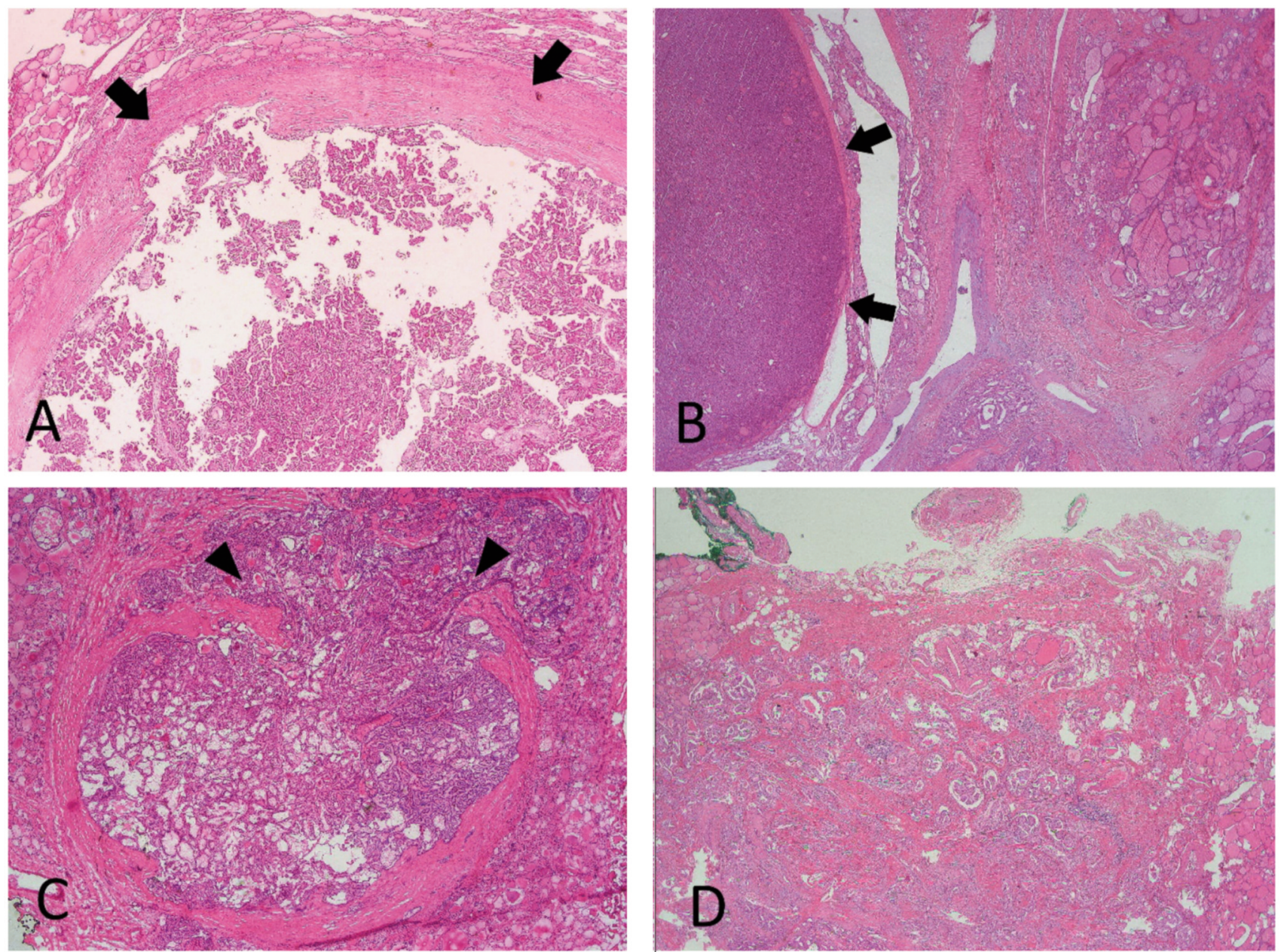

Figure 2. Tumor growth patterns. By definition, tumor growth pattern I describes a well-defined encapsulated growth (arrow) with a cystic or solid characteristic (A and B). An encapsulated growth with a partially pericapsular tumor extension (arrowhead) is growth pattern II(C), while an infiltrative tumor growth (stellate and spiculated margin) $(D)$ is growth pattern III. (Hematoxylin \& Eosin staining, original magnification $\times 40)$.

analyzed using logistic regression analysis. Statistical analysis was performed using the IBM SPSS Statistics for Windows, version 18.0 (IBM Corp., Armonk, NY, USA). Null hypotheses of no difference were rejected if $p$-Values were less than 0.05 , or, equivalently, if the $95 \%$ confidence intervals (CIs) of risk point estimates excluded 1.

\section{Results}

Patient Demographics. Of the 170 patients who underwent surgery for thyroid cancer during the study period, 147 $(86 \%)$ were female and $23(14 \%)$ were male. The mean age was 50.2 years (range $=23-80$ years) and the mean size of the primary tumors was $1.24 \mathrm{~cm} \quad$ (range=0.2-1.9 $\mathrm{cm}$ ) Postoperative transient hypocalcemia and temporary vocal fold paresis were noticed in 61 (36\%) and 6 patients $(3.5 \%)$, respectively; however, all of them recovered completely within six months, and there was no permanent hypocalcemia or permanent vocal fold paresis. Nodal involvement in the central and lateral neck occurred in 95 $(56 \%)$ and $23(13.5 \%)$ cases, respectively. Three kinds of TGPs, namely TGP I, II, and III, were observed in 15 (9\%), $99(58 \%)$, and 56 cases $(33 \%)$, respectively. Mean TF percentage was $28.6(0-90 \%)$. Iso- or hypoechogenicity and marked hypoechogenicity were measured in $80(47 \%)$ and $90(53 \%)$ of cases, respectively (Table I).

Clinicopathologic characteristics by TGPS/TF. TGPs II and III had more frequent ETE than TGP I ( $=13.3 \%$, II=63.6\%, and III=66.1\%; $p<0.005)$. The incidence of lateral neck LNM increased with a higher TGP $(\mathrm{I}=0 \%, \mathrm{II}=12.1 \%$, III=19.6\%) (Table II). In multivariate analysis, only the patient age was the significant determining factor for TGP III [ $p=0.043$, odds ratio $(\mathrm{OR})=1.057]$ (Table III). There were no significant differences in age, gender, tumor size, or central LNM affecting TF. 


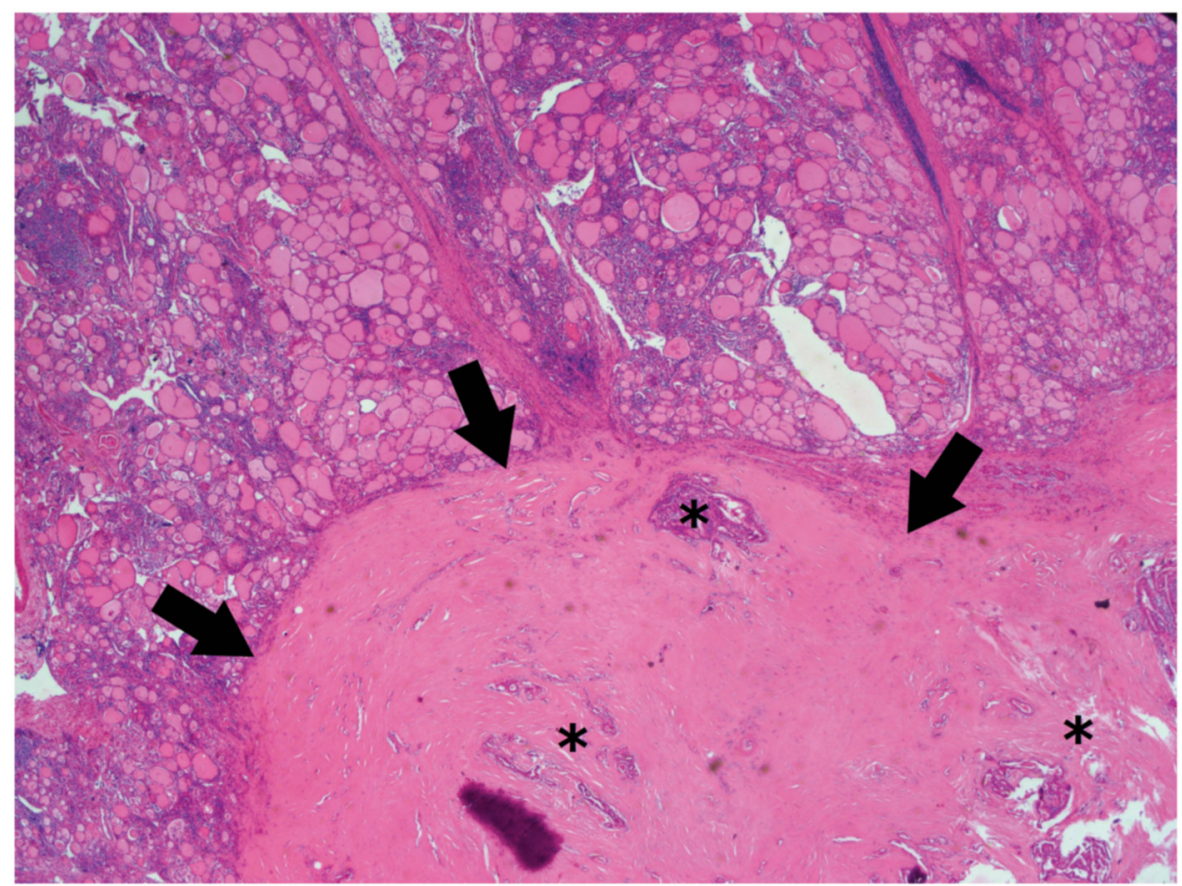

Figure 3. Intratumoral fibrosis. Multiple tumor foci of PTC (asterisks) are entrapped in dense collagenous fibrosis (arrows), the border of which is well demarcated from the surrounding thyroid tissue. (Hematoxylin \&Eosin staining, original magnification $\times 40$ ).

LNM by clinicopathological characteristics and TGPS/TF. Tumor size was the significant risk factor for LNM in the central compartment in the multivariate analysis $(p=0.007$, $\mathrm{OR}=5.036$ ). This was also the significant factor for lateral neck LNM in the univariate analysis, but the role of chance could not be ruled out in the multivariate analysis. Male gender and a higher percentage of TF were significant risk factors for lateral neck LNM in the multivariate analysis $(p=0.015, \mathrm{OR}=3.827 ; p=0.040, \mathrm{OR}=1.025)$ (Table IV).

US echogenicity by clinicopathological characteristics and $T G P S / T F$. Patient age, gender, and tumor size did not exhibit any significance with respect to the type of US echogenicity; however, TGP II/III and TF were the determining factors for the US marked hypoechogenicity in the univariate analysis. In the multivariate analysis, only TGP III and TF had significance $(p=0.033, \mathrm{OR}=4.838 ; p=0.049, \mathrm{OR}=1.020)($ Table V) .

\section{Discussion}

Many studies have been conducted to predict the aggressive behavior of PTC by histopathological analysis. Prominent hobnail features, loss of cohesiveness, and polarity are noted for tumor aggressiveness and LNM (9-12, 14). Tumor border is also a significant prognostic element of the aggressive behavior in PTC (18-20). Jung et al., have reported that the infiltrative tumor border is a strong predictive factor for LNM
Table I. Demographics and clinical characteristics of the 170 patients.

\begin{tabular}{lc}
\hline Age at diagnosis, years & $50.2 \pm 10.9(23-80)^{\mathrm{a}}$ \\
Gender & \\
Female & $147(86 \%)$ \\
Male & $23(14 \%)$ \\
Tumor size, mm & $7.4 \pm 3.6(2-20)^{\mathrm{a}}$ \\
Extrathyroidal extension & \\
$\quad$ Present & $102(60 \%)$ \\
Absent & $68(40 \%)$ \\
Nodal involvement & $95(56 \%)$ \\
Central neck metastasis & $23(13.5 \%)$ \\
Lateral neck metastasis & $15(9 \%)$ \\
Tumor growth patterns ${ }^{\mathrm{b}}$ & $99(58 \%)$ \\
I & $56(33 \%)$ \\
II & $28.6 \pm 18.3(0-90)^{\mathrm{a}}$ \\
III & \\
Tumoral fibrosis (\%) & $80(47 \%)$ \\
Ultrasound echogenecity & $90(53 \%)$ \\
Iso- or hypoechogenicity & \\
Marked hypoechogenicity & \\
\hline
\end{tabular}

${ }^{a}$ Mean \pm standard deviation (range). bI: A well-defined encapsulated growth with a cystic or solid characteristic; II: an encapsulated growth with partially pericapsular tumor extension; III: an infiltrative tumor growth.

(13). Moreover, lateral tubular growth and intraglandular disseminations are noted as significant risk factors for LNM (19). Tumor fibrosis is known to be associated with poor prognosis by increased tumor recurrence and distant metastasis 
Table II. Clinical characteristics by tumor growth patterns and tumor fibrosis.

No. Patients

\begin{tabular}{|c|c|c|c|c|c|}
\hline \multirow[b]{2}{*}{ Variables } & \multicolumn{4}{|c|}{ Tumor growth pattern } & \multirow[b]{2}{*}{ Tumor fibrosis $(\%)$} \\
\hline & I & II & III & $p$-Value & \\
\hline No. of patients & 15 & 99 & 56 & & 170 \\
\hline Age, years ${ }^{\mathrm{a}}$ & $46.4 \pm 10.5$ & $49.6 \pm 10.6$ & $52.4 \pm 11.2$ & 0.675 & - \\
\hline \multicolumn{6}{|l|}{ Gender } \\
\hline Male & $1 / 15(6.7 \%)$ & $15 / 99(15.2 \%)$ & $7 / 56(12.5 \%)$ & 0.649 & $26.7 \pm 13.2^{\mathrm{a}}$ \\
\hline Female & $14 / 15(93.3 \%)$ & $84 / 99(84.8 \%)$ & $49 / 56(87.5 \%)$ & & $28.9 \pm 19.0^{\mathrm{a}}$ \\
\hline Tumor size ${ }^{a}$ & $7.9 \pm 3.4$ & $7.4 \pm 3.3$ & $7.2 \pm 4.2$ & 0.777 & - \\
\hline Extrathyroidal extension & $2 / 15(13.3 \%)$ & $63 / 99(63.6 \%)$ & $40 / 56(66.1 \%)$ & $0.000^{*}$ & - \\
\hline Central neck metastasis & $6 / 15(40 \%)$ & $59 / 99(60 \%)$ & $30 / 56(53.6 \%)$ & 0.335 & 26.9 vs. $30.0^{\mathrm{b}}$ \\
\hline Lateral neck metastasis & $0 / 15(0 \%)$ & $12 / 99(12.1 \%)$ & $11 / 56(19.6 \%)$ & $\mathrm{NA}^{\mathrm{c}}$ & 27.6 vs. $35.4^{\mathrm{b}}$ \\
\hline
\end{tabular}

NA: Not applicable. ${ }^{\mathrm{a} M e a n} \pm$ standard deviation. ${ }^{\mathrm{b}}$ Mean of TF in no metastasis group $v s$. metastasis group. ${ }^{\mathrm{c} E s t i m a t i o n}$ of $p$-Value is implausible, because there are no occurrences of lateral neck metastasis in patients having a type I tumor growth pattern. *Statistically significant.

Table III. Logistic regression analysis of clinicopathological factors affecting tumor growth patterns.

\begin{tabular}{|c|c|c|c|c|c|c|c|}
\hline \multirow{2}{*}{\multicolumn{2}{|c|}{$\begin{array}{l}\text { Tumor growth } \\
\text { patterna }^{\text {a }}\end{array}$}} & \multicolumn{3}{|c|}{ Univariate } & \multicolumn{3}{|c|}{ Multivariate } \\
\hline & & OR & $95 \% \mathrm{CI}$ & $p$-Value & OR & $95 \% \mathrm{CI}$ & $p$-Value \\
\hline \multirow[t]{3}{*}{ II } & Age & 1.027 & $0.977-1.080$ & 0.291 & 1.029 & $0.979-1.082$ & 0.259 \\
\hline & Gender & 0.400 & $0.049-3.272$ & 0.393 & 0.398 & $0.048-3.275$ & 0.392 \\
\hline & Tumor size & 0.707 & $0.181-2.764$ & 0.618 & 0.608 & $0.149-2.473$ & 0.487 \\
\hline \multirow[t]{3}{*}{ III } & Age & 1.053 & $1.001-1.111$ & 0.047 & 1.057 & $1.002-1.116$ & 0.043 \\
\hline & Gender & 0.500 & $0.057-4.414$ & 0.533 & 0.500 & $0.056-4.488$ & 0.536 \\
\hline & Tumor size & 0.588 & $0.135-2.560$ & 0.479 & 0.452 & $0.099-2.057$ & 0.304 \\
\hline
\end{tabular}

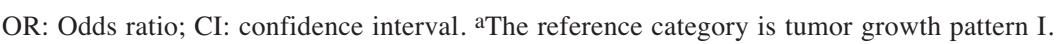

in colorectal and oral cavity cancer $(21,22)$. Also, extensive fibrosis in PTC can predict a more aggressive tumor behavior, such as regional or distant metastasis $(15,23)$.

Our study demonstrated that more aggressive growth patterns more frequently result in ETE and LNM within the lateral compartment. Multivariate analysis revealed that older age, one of the well-known prognostic factors of PTC, was a significant determinant for the most aggressive histological pattern, namely, TGP III. Furthermore, male gender and TF were significant independent risk factors for lateral neck LNM.

US is a powerful tool for the diagnosis of thyroid malignancy and the prediction of LNM, even though it is not widely used in the detection of central neck LNM due to its lower relative accuracy compared to its accuracy in detecting lateral neck LNM and ETE (24-27). Nevertheless, it has been reported that the US echogenicity of a tumor can be a predictive factor for the ETE and central neck LNM (7). Others have shown cases of PTC with LNM in the lateral compartment with US hypoechogenicity or marked hypoechogenicity in preoperative evaluation, which means there was no lateral neck LNM in PTC with isoechogenicity (8).

To the best of our knowledge, only a few studies have focused on the relationship between preoperative US echogenicity, tumor histological characteristics, and clinical manifestations such as regional LNM. Wang et al., have analyzed the associations of ultrasonographic margin status of PTC with histopathological parameters (28). It was noted that half of the malignant nodules had a well-defined boundary on the US and the remaining half had an illdefined border. Well-defined boundaries on the US were associated with well-defined histological margins, with or without the presence of an intact fibrous pseudo-capsule. Half of the malignant nodules with ill-defined boundaries on the US exhibited infiltration into the surrounding thyroid tissue, whereas the remaining half with ill-defined boundaries presented with irregular histological margins rather than infiltration (28). 
in vivo $35: 1633-1640(2021)$

Table IV. Logistic regression analysis of clinicopathologic factors and TGPS/TF for central and lateral lymph node metastasis (LNM).

\begin{tabular}{|c|c|c|c|c|c|c|c|c|c|c|c|c|}
\hline & \multicolumn{6}{|c|}{ Central LNM } & \multicolumn{6}{|c|}{ Lateral LNM } \\
\hline & \multicolumn{3}{|c|}{ Univariate } & \multicolumn{3}{|c|}{ Multivariate } & \multicolumn{3}{|c|}{ Univariate } & \multicolumn{3}{|c|}{ Multivariate } \\
\hline & OR & $95 \% \mathrm{CI}$ & $p$-Value & OR & $95 \% \mathrm{CI}$ & $p$-Value & OR & $95 \% \mathrm{CI}$ & $p$-Value & OR & $95 \% \mathrm{CI}$ & $p$-Value \\
\hline Age & 0.989 & $0.962-1.017$ & 0.440 & 0.977 & $0.948-1.008$ & 0.143 & 1.028 & 0.986-1.072 & 0.187 & 1.018 & $0.975-1.064$ & 0.410 \\
\hline Gender & 1.570 & $0.627-3.930$ & 0.335 & 1.420 & $0.537-3.752$ & 0.480 & 3.582 & $1.280-10.021$ & 0.015 & 3.827 & $1.291-11.343$ & 0.015 \\
\hline $\begin{array}{l}\text { Tumor } \\
\text { size, mm }\end{array}$ & 5.119 & $1.752-14.956$ & 0.003 & 5.036 & $1.562-16.233$ & 0.007 & 3.120 & $1.091-8.923$ & 0.034 & 2.703 & $0.851-8.589$ & 0.092 \\
\hline ETE & 2.010 & $1.078-3.750$ & 0.028 & 1.406 & $0.683-2.894$ & 0.355 & 2.067 & $0.771-5.543$ & 0.149 & 1.358 & $0.459-4.015$ & 0.580 \\
\hline \multicolumn{13}{|l|}{ TGP } \\
\hline I & 1 & & & 1 & & & $\mathrm{NA}^{\mathrm{a}}$ & & & $\mathrm{NA}^{\mathrm{a}}$ & & \\
\hline II & 2.212 & $0.730-6.702$ & 0.160 & 1.908 & $0.534-6.821$ & 0.320 & $\mathrm{NA}^{\mathrm{a}}$ & & & $\mathrm{NA}^{\mathrm{a}}$ & & \\
\hline III & 1.731 & $0.543-5.515$ & 0.354 & 1.650 & $0.423-6.445$ & 0.471 & NAa & & & $\mathrm{NA}^{\mathrm{a}}$ & & \\
\hline $\mathrm{TF}$ & 1.009 & $0.992-1.027$ & 0.285 & 1.406 & $0.683-2.894$ & 0.355 & 1.020 & $1.001-1.042$ & 0.061 & 1.025 & $1.001-1.049$ & 0.040 \\
\hline
\end{tabular}

OR: Odds ratio; CI: confidence interval; ETE: extrathyroidal extension; TGP: tumor growth pattern; TF: tumor fibrosis; NA: not applicable. aEstimation of odds ratios and CIs are implausible, because there are no occurrences of lateral LNM in patients having type I of tumor growth pattern.

Table V. Logistic regression analysis of clinicopathological factors and TGPS/TF for US echogenicity.

\begin{tabular}{|c|c|c|c|c|c|c|c|c|}
\hline \multirow{2}{*}{$\begin{array}{l}\text { No. of } \\
\text { patients }\end{array}$} & \multirow{2}{*}{$\begin{array}{c}\begin{array}{c}\text { Iso- or } \\
\text { hypoechogenicity }\end{array} \\
80\end{array}$} & \multirow{2}{*}{$\begin{array}{c}\begin{array}{c}\text { Marked } \\
\text { hypoechogenicity }\end{array} \\
90\end{array}$} & \multicolumn{3}{|c|}{ Univariate } & \multicolumn{3}{|c|}{ Multivariate } \\
\hline & & & OR & $95 \%$ CI & $p$-Value & OR & $95 \%$ CI & $p$-Value \\
\hline Age & $50.7 \pm 9.9$ & $49.9 \pm 11.8$ & 0.993 & $0.966-1.021$ & 0.639 & 0.988 & $0.959-1.018$ & 0.427 \\
\hline \multicolumn{9}{|l|}{ Gender } \\
\hline Female & $67 / 80(83.7 \%)$ & $80 / 90(88.9 \%)$ & 1 & & & 1 & & \\
\hline Male & $13 / 80(16.3 \%)$ & $10 / 90(11.1 \%)$ & 0.644 & $0.266-1.563$ & 0.331 & 0.650 & $0.260-1.626$ & 0.357 \\
\hline $\begin{array}{l}\text { Tumor } \\
\text { size, mm }\end{array}$ & $7.8 \pm 3.9$ & $7.0 \pm 3.2$ & 0.536 & $0.225-1.278$ & 0.159 & 0.590 & $0.239-1.457$ & 0.252 \\
\hline \multicolumn{9}{|l|}{ TGP } \\
\hline $\mathrm{I}$ & $12 / 80(15.0 \%)$ & $3 / 90(3.3 \%)$ & 1 & & & 1 & & \\
\hline II & $47 / 80(58.7 \%)$ & $52 / 90(57.8 \%)$ & 4.426 & $1.179-16.653$ & 0.028 & 3.268 & $0.818-13.048$ & 0.094 \\
\hline III & $21 / 80(26.3 \%)$ & $35 / 90(38.9 \%)$ & 6.667 & $1.687-26.393$ & 0.007 & 4.838 & $1.133-20.660$ & 0.033 \\
\hline $\mathrm{TF}, \%$ & $24.5 \pm 13.5$ & $32.3 \pm 21.2$ & 1.026 & $1.007-1.046$ & 0.007 & 1.020 & $1.010-1.040$ & 0.049 \\
\hline
\end{tabular}

OR: Odds ratio; CI: confidence interval; TGP: tumor growth pattern; TF: tumor fibrosis.

In this study, we investigated the relationship between aggressive histological features, such as TGPs and TF, and clinical manifestations, such as LNM in the central and lateral neck. Univariate analysis revealed that TGP II/III and the percentage of TF were the significant factors determining US marked hypoechogenicity, while in the multivariate analysis, TGP III and TF were the significant determinants of marked hypoechogenicity. Taken together, it can be reasonably inferred that tumors exhibiting more invasive TGPs and a higher percentage of $\mathrm{TF}$, which may be associated with more frequent ETE and lateral neck LNM, can have a marked hypoechogenicity on the preoperative US.

The limitations of this study are the lack of i) a large number of cases and ii) long-term follow-up data for regional recurrences or distant metastasis. Despite this, based on the relationship between US echogenicity, histological tumor behavior, and clinical manifestations, this study can provide a more comprehensive understanding of the tumor behavior of PTC concerning the preoperative US echogenicity. This information can be used in personalized treatment strategies for men or older patients.

In conclusion, tumors with more invasive TGPs had more frequent ETE and lateral neck LNM. Older age was the significant determinant for an aggressive growth pattern, while male gender and a higher percentage of TF were significant independent risk factors for the lateral neck LNM. Marked hypoechogenicity of the tumor on US was significantly affected by TGPs and TF. Therefore, it is thought that PTC 
with marked hypoechogenicity can have a more aggressive tumor behavior and lead to advanced clinical staging. As such, it can be used as a more personalized and optimized treatment strategy in the treatment of PTC by offering a preoperative prediction of tumor behavior.

\section{Conflicts of Interests}

The Authors declare no competing interests.

\section{Authors' Contributions}

YSL, JCL and IJK conceived and designed the study. YSL, SMS, SSK and DHS analyzed the data. YSL and BJL drafted the manuscript. All Authors revised the article for important intellectual content, reviewed the data and their analyses and approved this article.

\section{Acknowledgements}

This work was supported by the Dongguk University Research Fund of 2015 .

\section{References}

1 Lim YS, Choi SW, Lee YS, Lee JC, Lee BJ, Wang SG, Son SM, Kim IJ and Shin DH: Frozen biopsy of central compartment in papillary thyroid cancer: Quantitative nodal analysis. Head Neck 35(9): 1319-1322, 2013. PMID: 22907829. DOI: 10.1002/ hed.23129

2 Wada N, Duh QY, Sugino K, Iwasaki H, Kameyama K, Mimura T, Ito K, Takami $\mathrm{H}$ and Takanashi Y: Lymph node metastasis from 259 papillary thyroid microcarcinomas: Frequency, pattern of occurrence and recurrence, and optimal strategy for neck dissection. Ann Surg 237(3): 399-407, 2003. PMID: 12616125. DOI: $10.1097 / 01 . S L A .0000055273 .58908 .19$

3 Ricarte-Filho J, Ganly I, Rivera M, Katabi N, Fu W, Shaha A, Tuttle RM, Fagin JA and Ghossein R: Papillary thyroid carcinomas with cervical lymph node metastases can be stratified into clinically relevant prognostic categories using oncogenic BRAF, the number of nodal metastases, and extranodal extension. Thyroid 22(6): 575-584, 2012. PMID: 22471242. DOI: $10.1089 /$ thy.2011.0431

4 Leboulleux S, Rubino C, Baudin E, Caillou B, Hartl DM, Bidart JM, Travagli JP and Schlumberger M: Prognostic factors for persistent or recurrent disease of papillary thyroid carcinoma with neck lymph node metastases and/or tumor extension beyond the thyroid capsule at initial diagnosis. J Clin Endocrinol Metab 90(10): 5723-5729, 2005. PMID: 16030160. DOI: 10.1210/jc.2005-0285

5 Park YM, Wang SG, Lee JC, Shin DH, Kim IJ, Son SM, Mun $\mathrm{M}$ and Lee BJ: Metastatic lymph node status in the central compartment of papillary thyroid carcinoma: A prognostic factor of locoregional recurrence. Head Neck 38(Suppl 1): E1172E1176, 2016. PMID: 26268535. DOI: 10.1002/hed.24186

6 Chow SM, Law SC, Chan JK, Au SK, Yau S and Lau WH: Papillary microcarcinoma of the thyroid-Prognostic significance of lymph node metastasis and multifocality. Cancer 98(1): 3140, 2003. PMID: 12833452 . DOI: $10.1002 /$ cncr.11442
7 Kim SS, Lee BJ, Lee JC, Kim SJ, Lee SH, Jeon YK, Kim BH, Kim YK and Kim IJ: Preoperative ultrasonographic tumor characteristics as a predictive factor of tumor stage in papillary thyroid carcinoma. Head Neck 33(12): 1719-1726, 2011. PMID: 22076977. DOI: 10.1002/hed.21658

8 Lee YS, Lim YS, Lee JC, Wang SG, Son SM, Kim SS, Kim IJ and Lee BJ: Ultrasonographic findings relating to lymph node metastasis in single micropapillary thyroid cancer. World J Surg Oncol 12: 273, 2014. PMID: 25169012. DOI: 10.1186/14777819-12-273

9 Asioli S, Erickson LA, Righi A and Lloyd RV: Papillary thyroid carcinoma with hobnail features: histopathologic criteria to predict aggressive behavior. Hum Pathol 44(3): 320-328, 2013. PMID: 23036367. DOI: 10.1016/j.humpath.2012.06.003

10 Asioli S, Erickson L, Sebo T, Zhang J, Jin L, Thompson G and Lloyd R: Papillary thyroid carcinoma with prominent hobnail features: A new aggressive variant of moderately differentiated papillary carcinoma. A clinicopathologic, immunohistochemical, and molecular study of eight cases. American Journal of Surgical Pathology 34(1): 44-52, 2021. DOI: 10.1097/PAS.0b013 e3181c46677

11 Bai Y, Kakudo K, Nakamura M, Ozaki T, Li Y, Liu Z, Mori I, Miyauchi A and Zhou G: Loss of cellular polarity/cohesiveness in the invasive front of papillary thyroid carcinoma and periostin expression. Cancer Lett 281(2): 188-195, 2009. PMID: 19321256. DOI: 10.1016/j.canlet.2009.02.043

12 Chung YJ, Lee JS, Park SY, Park HJ, Cho BY, Park SJ, Lee SY, Kang KH and Ryu HS: Histomorphological factors in the risk prediction of lymph node metastasis in papillary thyroid carcinoma. Histopathology 62(4): 578-588, 2013. PMID: 23379688. DOI: $10.1111 /$ his.12025

13 Jung YY, Lee CH, Park SY, Park HJ, Min HS, Won JK, Kim BS and Ryu HS: Characteristic tumor growth patterns as novel histomorphologic predictors for lymph node metastasis in papillary thyroid carcinoma. Hum Pathol 44(12): 2620-2627, 2013. PMID: 24139209. DOI: 10.1016/j.humpath.2013.07.025

14 Liu Z, Kakudo K, Bai Y, Li Y, Ozaki T, Miyauchi A, Taniguchi $\mathrm{E}$ and Mori I: Loss of cellular polarity/cohesiveness in the invasive front of papillary thyroid carcinoma, a novel predictor for lymph node metastasis; possible morphological indicator of epithelial mesenchymal transition. J Clin Pathol 64(4): 325-329, 2011. PMID: 21296795. DOI: 10.1136/jcp.2010.083956

15 Niemeier LA, Kuffner Akatsu H, Song C, Carty SE, Hodak SP, Yip L, Ferris RL, Tseng GC, Seethala RR, Lebeau SO, Stang MT, Coyne C, Johnson JT, Stewart AF and Nikiforov YE: A combined molecular-pathologic score improves risk stratification of thyroid papillary microcarcinoma. Cancer 118(8): 2069-2077, 2012. PMID: 21882177. DOI: 10.1002/cncr.26425

16 Cooper DS, Doherty GM, Haugen BR, Kloos RT, Lee SL, Mandel SJ, Mazzaferri EL, McIver B, Sherman SI, Tuttle RM and American Thyroid Association Guidelines Taskforce.: Management guidelines for patients with thyroid nodules and differentiated thyroid cancer. Thyroid 16(2): 109-142, 2006. PMID: 16420177. DOI: 10.1089/thy.2006.16.109

17 Kim EK, Park CS, Chung WY, Oh KK, Kim DI, Lee JT and Yoo HS: New sonographic criteria for recommending fine-needle aspiration biopsy of nonpalpable solid nodules of the thyroid. AJR Am J Roentgenol 178(3): 687-691, 2002. PMID: 11856699. DOI: $10.2214 /$ ajr.178.3.1780687 
18 Mai KT, Perkins DG, Yazdi HM, Commons AS, Thomas J and Meban S: Infiltrating papillary thyroid carcinoma: Review of 134 cases of papillary carcinoma. Arch Pathol Lab Med 122(2): 166-171, 1998. PMID: 9499361

19 Jung CK, Kang YG, Bae JS, Lim DJ, Choi YJ and Lee KY: Unique patterns of tumor growth related with the risk of lymph node metastasis in papillary thyroid carcinoma. Mod Pathol 23(9): 1201-1208, 2010. PMID: 20543822. DOI: 10.1038/ modpathol.2010.116

20 Tang W, Nakamura Y, Zuo H, Yasuoka H, Yang Q, Wang X, Nakamura M, Mori I, Miyauchi A and Kakudo K: Differentiation, proliferation and retinoid receptor status of papillary carcinoma of the thyroid. Pathol Int 53(4): 204-213, 2003. PMID: 12675763. DOI: $10.1046 / j .1320-5463.2003 .01456 . x$

21 Tsuchihashi K, Nakatsugawa M, Kobayashi JI, Sasaya T, Morita R, Kubo T, Kanaseki T, Tsukahara T, Asanuma H, Hasegawa T, Hirano H, Miyazaki A, Hirohashi Y and Torigoe T: Borderline microenvironment fibrosis is a novel poor prognostic marker of oral squamous cell carcinoma. Anticancer Res 40(8): 4319-4326, 2020. PMID: 32727759. DOI: 10.21873 /anticanres. 14434

22 Kondo T, Okabayashi K, Hasegawa H, Tsuruta M, Shigeta K and Kitagawa Y: The impact of hepatic fibrosis on the incidence of liver metastasis from colorectal cancer. Br J Cancer 115(1): 3439, 2016. PMID: 27280634. DOI: 10.1038/bjc.2016.155

23 Pellegriti G, Scollo C, Lumera G, Regalbuto C, Vigneri R and Belfiore A: Clinical behavior and outcome of papillary thyroid cancers smaller than $1.5 \mathrm{~cm}$ in diameter: Study of 299 cases. J Clin Endocrinol Metab 89(8): 3713-3720, 2004. PMID: 15292295. DOI: $10.1210 /$ jc.2003-031982

24 Ito Y, Tomoda C, Uruno T, Takamura Y, Miya A, Kobayashi K, Matsuzuka F, Kuma K and Miyauchi A: Preoperative ultrasonographic examination for lymph node metastasis: Usefulness when designing lymph node dissection for papillary microcarcinoma of the thyroid. World J Surg 28(5): 498-501, 2004. PMID: 15085396. DOI: 10.1007/s00268-004-7192-Z
25 Chae BJ, Jung CK, Lim DJ, Song BJ, Kim JS, Jung SS and Bae JS: Performing contralateral central lymph node dissection in papillary thyroid carcinoma: A decision approach. Thyroid 21(8): 873-877, 2011. PMID: 21745104. DOI: 10.1089/thy.2010.0214

26 Kim HJ, Lee HJ, Jung JH, Kim WW, Park JY, Shin KM, Kim WH and Cho SH: Ultrasound assessment of synchronous thyroid nodules in patients with papillary thyroid cancer: A nodule-bynodule analysis between ultrasound and pathology. Anticancer Res 40(3): 1779-1786, 2020. PMID: 32132087. DOI: 10.21873/ anticanres.14132

27 Papapostolou KD, Evangelopoulou CC, Ioannidis IA, Kassi GN, Morfas KS, Karaminas NI and Karga HJ: Taller-than-wide thyroid nodules with microcalcifications are at high risk of malignancy. In Vivo 34(4): 2101-2105, 2020. PMID: 32606189. DOI: 10.21873 /invivo.12014

28 Wang Y, Li L, Wang YX, Feng XL, Zhao F, Zou SM, Hao YZ, Ying JM and Zhou CW: Ultrasound findings of papillary thyroid microcarcinoma: A review of 113 consecutive cases with histopathologic correlation. Ultrasound Med Biol 38(10): 16811688, 2012. PMID: 22920548. DOI: 10.1016/j.ultrasmedbio. 2012.05.019
Received January 31, 2021

Revised February 22, 2021 Accepted March 4, 2021 